\section{Autosomal recessive ataxia}

Mrissa et al. (p. 1408) report genetic studies on a large Tunisian family with early onset ataxia and retained tendon reflexes. After excluding linkage to other autosomal recessive ataxia loci (Friedreich's, vitamin E deficiency, and the SCAs), they established linkage to chromosome 13q11-12. This is the locus of a somewhat different phenotype in Quebec (ARSACS). The accompanying editorial by Pulst and Filla (p. 1400) reviews the molecular defects of autosomal recessive ataxias and points out why autosomal dominant SCAs often appear to be recessive.

Outcome of oligodendroglioma: Natural history versus treatment

Olson et al. (p. 1442) reviewed the Memorial Sloan-Kettering experience with 77 oligodendroglioma and 29 mixed glioma patients. There was a remarkably long period of stability without treatment in many patients. Because the toxicity and complications in those given treatment were substantial, the authors advocate deferring treatment until clinically necessary. The accompanying editorial by Cairncross (p. 1402) considers the evolution of thinking that has led to a consensus for delaying treatment and reviews the developing management strategies that will eventually justify early treatment.

\section{Immune-mediated neuropathy} and encephalomyelitis

Jorens et al. (p. 1433) describe a 3 -year-old boy with fulminant acute disseminated encephalomyelitis (ADEM). They found evidence of in vivo expansion of blood $\mathrm{T}$ cells that reacted to myelin basic protein. These cells showed cross-reactivity to Streptococcus pyogenes exotoxin. Thus, severe inflammatory demyelination culminating in ADEM may have resulted from induction of $\mathrm{T}$ cells that reacted to myelin.

- Three articles examine questions of antibody association with peripheral neuropathy. Dabby et al. (p. 1448) surveyed 450 neuropathy patients for antisulfatide antibodies. Twentyfive patients had extremely high titers $(>25,600)$. No specific syndrome was identified; sensory, sensorimotor, and demyelinating neuropathies were each observed. It is unclear if sulfatide antibodies are pathogenic. Ang et al. (p. 1453) examined whether cytomegalovirus (CMV)-infected fibroblasts contain epitopes that are recognized by Guillain-Barré syndrome (GBS) patient sera. CMV is one of the viral infections associated with subsequent GBS. They found that serum anti-GM2 antibodies that occur in GBS patients recognize CMV antigens in infected tissues. These observations support the hypothesis of epitopic mimicry in the pathogenesis of GBS. Kanda et al. (p. 1459) studied sural nerve specimens from patients with chronic inflammatory demyelinating polyneuropathy (CIDP) and GBS who had antiglycosphingolipid (GSL) antibodies. CIDP and GBS controls without GSL antibodies and other controls were also studied. There was evidence of antibody-positive patients. Van den Berg-Vos et al. (p. 1518) studied the effect of interferon- $\beta 1 \mathrm{a}$ in nine patients with multifocal motor neuropathy who had previously responded to IV immunoglobulin (IVIg). In three patients, improvement was noted to an extent greater than that with IVIg. In six patients, there was no benefit.
Frontal lobe epilepsy

Janszky et al. (p. 1470) studied the relationship between EEG signs, MRI findings, and seizure characteristics and the subsequent surgical outcome in 61 patients with frontal lobe epilepsy. Thirty of the patients became seizure-free. Patients without generalized EEG abnormalities were most likely to become seizure-free.

\section{Instant replay analysis: Concussions and football} McCrory and Berkovic (p. 1488) studied the 102 videotapes of acute concussive injuries that occurred in the Australian Football League (234 subjects had concussive injury). There was only one patient with a tonicclonic convulsion, but tonic posturing and clonic movements were frequent. Loss of consciousness was predictive of tonic posturing.

\section{APOE $\varepsilon 4$ and memory loss Dik et al. (p. 1492) tested mem- ory in 1243 elderly Dutch sub- jects (age 62 to 85 years) whose APOE status and Mini-Mental State Examination Score had been characterized. They re- tested subjects after 3 years. The APOE $\varepsilon 4$ allele was associated with further memory decline in those with initial cognitive impair- ment in subjects both younger and older than 75 years of age.}

\section{Cognitive decline in heredi- tary spastic paraplegia Byrne et al. (p. 1510) studied five families with chromosome $2 \mathrm{p}$-linked hereditary spastic paraplegia (HSP) (the most com- mon form of pure HSP). Cogni- tive decline was evident in subjects linked to the HSP locus, antedating other signs of HSP.}




\section{Neurology}

\section{April 11 Highlights}

Neurology 2000;54;1399

DOI 10.1212/WNL.54.7.1399

\section{This information is current as of April 11, 2000}

\section{Updated Information \&} Services

Permissions \& Licensing

\section{Reprints}

including high resolution figures, can be found at: http://n.neurology.org/content/54/7/1399.full

Information about reproducing this article in parts (figures,tables) or in its entirety can be found online at:

http://www.neurology.org/about/about_the_journal\#permissions

Information about ordering reprints can be found online:

http://n.neurology.org/subscribers/advertise

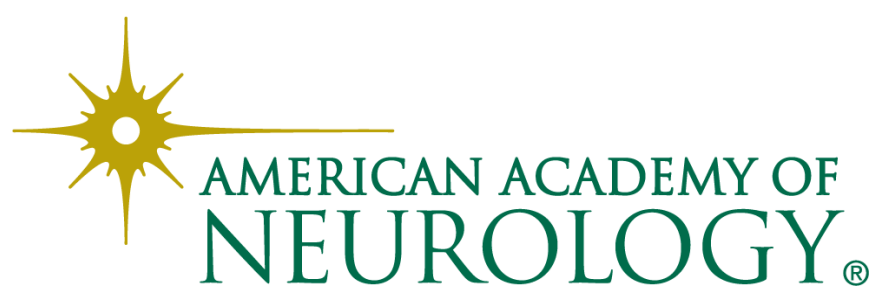

